\title{
Motoric Competence of Children with Specific Language Impairment: Variability and Effect of different Variables
}

\author{
Original Hassnaa Othman Mohammed, Reham Senosy, Shimaa Abdallah El-Sayed, Maisa \\ Article Nasr Farid
}

Department of the Medical Studies for Children, Faculty of Postgraduate Childhood Studies, Ain Shams University, Egypt.

\begin{abstract}
Background: The heterogeneous clinical presentation of children with Specific Language Impairment (SLI) turned the wheel of clinical research work toward verification of the nature of this disorder. Tools that assess language skills among children with language delay of unidentified causes should be overlooked, updated and standardized in order to help in understanding language development in relation to other developmental profile.

Patients and Methods: A comparative cross-sectional study carried on in the period between January 2017 and January 2019. Two groups of children were examined: 20 children previously diagnosed by exclusionary and inclusionary criteria as children with SLI and 40 (20 males and 20 females) were normally developed children matching the socio-demographic data of children in the first group. They were subjected to an assessment protocol that included: Standardized Arabic test (Modified Preschool Language Scale $-4^{\text {th }}$ edition Arabic form (PLS-4) and assessment of gross and fine motor skills by developmental scale of preschool children (Arabic standardized LAP)).

Results: Children with SLI were significantly impaired in the gross-motor developmental quotient as well as their finemotor developmental quotient. Delayed developmental quotient in the motoric domains were mainly related to late age of presentation of language deficit, first order of birth, increased the gap between language age and chronological age. Conclusion: SLI showed varied degrees of motoric deficit either on the gross aspects or fine one. This deficit was related to some aspects of the disorder.
\end{abstract}

Key Words: Developmental assessment, motoric development, SLI.

Received: 14 October 2020, Accepted: 30 October 2020

Corresponding Author: Hassnaa Othman Mohammed, MD, Department of the Medical Studies for Children, Faculty of Postgraduate Childhood Studies, Ain Shams University, Egypt, Tel.: +201066778915, E-mail: drmelwardany@yahoo.com

ISSN: 2090-0740, March 2021 Vol.22, No.1

\section{INTRODUCTION}

The degree of involvement of the motoric aspect among children with SLI could markedly assist researchers in determining the developmental profile among this population. This research work demonstrated the complex and multifaceted nature of the relation between language and motoric development ${ }^{[1-3]}$. Such studies among children with SLI were considered as the most perfect situation to understand the role of motor development among children with atypically developed language.

Most of those with Specific Language Impairment showed variable degrees of affection of many developmental aspects which usually not well considered during conventional assessment of children with SLI (e.g. executive functions impairment, non-verbal cognitive deficit, motoric aspects..etc.). Many evidences supported the view of motoric sub-normality among children with SLI.
Developmentally, despite of specificity of developmental pathway for each area, some motor skills are prerequisite for language development. Leonard and Hill[ ${ }^{[4]}$ and Iverson ${ }^{[5]}$ collected many evidences dated early in the child's development which supported the relation between language and motoric development. This relation appeared in (1) - Synchronization between the rhythmic arm movement and the canonical babbling ${ }^{[5]},(2)$ - Development from crawling to walking produced more advanced social interaction behavior in infants (Karasik et al. ${ }^{[6]}$; Clearfield et al. ${ }^{[7]}$ Campos et al. ${ }^{[8]}$ ), (3) - Studies showed that training of manual manipulation and exploration of objects in very young infants facilitate markedly the development of the pattern of face preference. This finding suggested that motoric training increase the rate of maturation of shared attention Libertus and Needham ${ }^{[9-10]}$, lastly (4) - The very strong association between emergence of language and manual gestures; MacNeilage ${ }^{[11]}$ reported one of the most shinny evidences that point to the relation between language and motoric development. 
These set of evidences were further supported by instrumental assessment, Wang et al. ${ }^{[1]}$ reported that motor and communication skills at 18 months were equally good predictor of later communication skills. Cheng et al. ${ }^{[3]}$ reported that children with poor motor skills recorded poor performance on a standardized language test and experimental test of emotion comprehension. Furthermore, a strong correlation between speech fluency and precision of the manual motor skills was found by Gernsbacher et al. ${ }^{[12]}$. Merriman and Barnett ${ }^{[13]}$ found that gross motor score were significantly correlated with auditory comprehension, verbal abilities and total communication score.

The association between language and motoric skill proved neuro-anatomically. Researchers found that language and motoric acts shared a neuro-anatomical correlates $^{[14-17]}$.

Weismer et al ${ }^{[18]}$ supposed that children with delayed language development of unidentified causes are a victim of a broader underlying neurodevelopmental deficit. Such deficit plays a role in development of multiple developmental deficits which present themselves among these children either clinically or sub-clinically. Others explained the multiplicity of developmental deficit among children with SLI by the existence of more general rhythmic out-put deficit. ${ }^{[19-21]}$

Despite that the motoric deficit among children with SLI was thoroughly studied among literature, many aspects in this relation remained unclear and need further assessment. The variability of the degree of this deficit and the correlation between motoric deficit among children with SLI and many different aspects of this disorder was the theme of the current work.

\section{AIM OF THE STUDY:}

An objective assessment of the motoric development (both the gross motor and the fine motor aspects) among children with SLI was carried out to compare their results with a control group and define a correlation between different variables among these children and their motoric development score.

\section{PATIENTS AND METHODS:}

Approval of the Ethics Committee of Faculty of Medicine- Ain Shams University was taken. The study was a cross-sectional comparative study that examined a group of twenty children (16 males and 4 females) their ages were from 2 to 5 years, they were previously diagnosed with SLI during the last three months. The objectives of the study were illustrated to either one or two of the parents. A written consent was taken from the caregiver who accompanies the child during the assessment process.
The results of children in the SLI group were compared to the results of children in a comparable control group of 40 children (20 males and 20 females) in the same age range of the SLI group of children.

- Children in the SLI group received their diagnosis after passing through an assessment protocol that was applied by the Phoniatrics Unit, ENT department, Faculty of Medicine, Ain Shams University that included: A) - Personal History taking (name, gender, handedness, schooling, parental consanguinity and similar conditions in the family). B) - perinatal, developmental and past history (head trauma, fits, ear disease \& others). C) - History of present illness. D) - Communicative assessment was carried by a phoniatrics consultant subjectively in order to determine the passive language skills (eye contact, comprehension of simple and complex commands), active language skills (the length of sentences, the syntax, the semantic, the phonology and the pragmatics). Communicative skills were collected during a semistructured setting that was equipped with material which could facilitate gathering information regarding child attention and comprehension. The diagnosis of SLI was reached through inclusionary as well as exclusionary criteria. Although the cognitive abilities could be assessed subjectively, a routine objective cognitive assessment of the children's cognitive abilities was carried through standardized Arabic cognitive assessment tools: StanfordBinet Intelligence Scales-fifth Edition-The Arabic version $^{[22]}$ (it yields three distinct scores Verbal IQ, Non Verbal IQ and total IQ) and Vineland Adaptive Behavior Scales (VABS) to assess the adaptive functions. The test includes four subdomains (communication, social skills, daily living, and motor skills) and a composite adaptive behavioral score ${ }^{[23]}$.

The followed assessment protocol was applied on the two groups of children. It included (1)- language assessment via standardized Arabic test (Modified Preschool Language Scale $-4^{\text {th }}$ edition Arabic form (PLS-4)) which gives language age (receptively and expressively) and determines the type of $\mathrm{SLI}^{[24]}$ and (2)- Developmental assessment by developmental scale of Egyptian preschool children (Arabic standardized LAP) ${ }^{[25]}$. Thereafter, their developmental quotient in Gross motor and Fine motor aspects was determined. The assessment sessions was divided into two- three sessions.

\section{Tools}

The developmental scale of Egyptian preschool children $^{[25]}$ is a standardized, norm - referenced developmental assessment tool for children between 2 to 6 years. This instrument is based on translation and standardization of two other instruments. Those were Learning Accomplishment Profile for children from 3-6 years $^{[26]}$ and the Early Learning Accomplishment Profile for 
children from birth to 3 years ${ }^{[27-28]}$. These instruments were an early intervention assessment for both children with and without disabilities ${ }^{[29]}$. The instrument was centered on seven developmental areas: (Gross motor, Fine motor, Prewriting, Cognitive, Language and Self-help). They were considered by researchers as the most commonly used tool for the assessment of cognitive abilities and the second commonly popular for fine motor, social emotional and adaptive behavioral development. LAP authors assumed that learning took place in sequential steps with each step rooted in the mastery of lower level pre-requested skills. The instrument is considered as a performance based tool (i.e. it depends on observation of the examiner to the child's performance and gathers information from the parents who are observing the child with limited relay on language skills of the child). It is composed of skills that are arranged in normal developmental sequences moving upward from simple to complex learned behaviors. The starting point for each child is their chronological age in months. Then, the rater scored presence $(+)$ for the observed behavior during assessment and by mother questioning and absence (-) for behavior which is not observed during evaluation and the mother signifies its absence in the child daily behaviors. The basal criteria are gaining $(+)$ scores for 8 consecutive items successfully completed and the ceiling criteria are gaining (-) scores for 5 consecutive items. The raw score is the subtraction between the ceiling and the basal number. The raw score is converted into a standardized score through a normative table. The corresponding description of the developmental quotient is then obtained from the conversion table. Despite of its uniqueness in providing an Egyptian based criterion reference developmental assessment tool, this tool is not popular between researchers in the field of the developmental assessment in Egypt.

The second tool that was used in the current work was Modified pre-school language scale (Arabic edition) $)^{[24]}$ Modified Preschool Language Scale fourth edition has two standardized subscales and two supplemental measures. The two standardized subscales are auditory comprehension subscale (Auditory comprehension subtest is composed of 62 items which are distributed at different age groups), and expressive communication subscale (expressive communication subtest is composed of 71 items which are also distributed at different age groups). The two supplemental measures are articulation screener and caregiver questionnaire. Modified PLS-4 is used to identify language abilities and disabilities in children and to establish whether or not remediation and language therapy is needed. The test enables the examiner to classify children according to the most salient characteristics of their expressive language, interactive behavior and comprehension. It has the ability to classify children with SLI into: syntactic phonological type, phonological programming and semantic syntactic type $^{[30]}$. N.B: (cases with sever verbal dyspraxia and severe auditory agnosia were excluded from the current work).
Microsoft Excel (2013) was used for data entry and the statistical package for social science (SPSS) version 21 (SPSS, Armonk, New York: International Business Machines Corporation) ${ }^{[31]}$ was used for data analysis. Simple descriptive statistics (arithmetic mean and standard deviation) are used for the quantitative data and frequencies used for qualitative data. The bivariate relationship was displayed in cross-tabulations and comparison of proportions was performed using the chi-square and Fisher's exact tests where appropriate. T-independent, one-way ANOVA, and post-hook tests were used to compare normally distributed quantitative data. The level of significance was set at probability $(P$ value $<0.05)$

\section{RESULTS:}

The current work was a cross sectional case-control study that was conducted on two groups of children in the period between January 2017 and January 2019. The control group was 40 children (20 males and 20 females) and was comparable in their socio-demographic data to children in the case group see (Table 1). The second group was a sample of 20 children their mean age was 3.75 years $( \pm 1.44)$ details are shown in (Table 2). Children in both groups were subjected to (1)- Assessment of language aptitude (receptive and expressive), and (2)- Developmental assessment in the area of gross motor and fine motor abilities. Language assessment revealed that children in the control group obtained a language age that matched the chronological age. The mean receptive language age for children in the case group was 2.84 years $( \pm 0.76)$ while the mean expressive age for the whole sample was 1.8 years $( \pm 0.2)$ see (Table 3$)$. According to the detailed findings of the PLS-4, children with SLI were further classified into phonological programming (40\%), syntactic phonological (40\%), and semantic pragmatic (20\%). Developmental assessment for the two groups showed that children in the control group received the label of normally developed in $90 \%$ of the children in that group regarding his/her gross motor and fine motor skills. Children in the case group showed that only $30 \%$ of the studied sample was normally developed (DQ was matching the standard score of the test). However, the gross motor abilities were mildly impaired in $65 \%$ of the children with SLI. Only one patient $(5 \%)$ was significantly delayed regarding his/her gross motor abilities. The fine motor abilities were normal in $20 \%$, mild delayed in $75 \%$ and significantly delayed in $5 \%$ see (Table 4). Comparative study revealed that children in the case group were significantly different from children in the control group (in their language ages, gross motor developmental quotient, and fine motor developmental quotient) (Table 3). Further analysis of the data was carried on in order to correlate certain variables in children with SLI and their developmental quotient in the gross motor and the fine motor domains see (Table $5 \& 6$ ). 
Table 1: the socio demographic data of the control group

\begin{tabular}{|c|c|c|c|c|c|c|c|c|}
\hline \multirow{2}{*}{$\begin{array}{l}\text { The whole } \\
\text { sample }\end{array}$} & \multirow[b]{2}{*}{$\begin{array}{c}\text { Mean age } \\
\text { (years) (SD) }\end{array}$} & \multicolumn{3}{|c|}{ Sex distribution } & \multirow[b]{2}{*}{$\begin{array}{l}\text { Mean receptive } \\
\text { lang. age (years) }\end{array}$} & \multirow[b]{2}{*}{$\begin{array}{c}\text { Mean expressive lang. } \\
\text { age (years) (SD) }\end{array}$} & \multirow[b]{2}{*}{$\begin{array}{l}\text { Mean gross } \\
\text { motor t-score }\end{array}$} & \multirow{2}{*}{$\begin{array}{l}\text { Mean fine } \\
\text { motor t-score }\end{array}$} \\
\hline & & type & No. & $\begin{array}{l}\text { Mean age } \\
\text { (years) }(\mathrm{SD})\end{array}$ & & & & \\
\hline \multirow{2}{*}{40} & \multirow{2}{*}{3.80} & Male & 20 & $3.70( \pm 0.47)$ & $3.35( \pm 0.51)$ & $3.49( \pm 0.42)$ & $59.80( \pm 4.74)$ & $55.45( \pm 5.7)$ \\
\hline & & Female & 20 & $3.90( \pm 0.31)$ & $3.55( \pm 0.47)$ & $3.68( \pm 0.55)$ & $58.20( \pm 4.61)$ & $55.45( \pm 4.63)$ \\
\hline
\end{tabular}

The table described the socio-demographic data of the control group. There was a non-significant statistical difference between the mean values of different variables of both sexes among the control group, i.e. (age, receptive language age, expressive language age, mean value of t-score of the gross motoric abilities, and the mean value of the fine motoric abilities of the fine motor abilities). The significance of differences between these variables $P=0.12,0.20,0.214,0.286$ and 1.00 ) consecutively.

Table 2: The table described the socio-demographic data of the SLI group

\begin{tabular}{|c|c|c|c|c|c|c|c|c|}
\hline \multirow{2}{*}{$\begin{array}{l}\text { The whole } \\
\text { sample }\end{array}$} & \multirow{2}{*}{$\begin{array}{c}\text { Mean age } \\
\text { (years) (SD) }\end{array}$} & \multicolumn{3}{|c|}{ Sex distribution } & \multirow{2}{*}{$\begin{array}{l}\text { Mean receptive } \\
\text { lang. age (years) }\end{array}$} & \multirow{2}{*}{$\begin{array}{c}\text { Mean expressive lang. } \\
\text { age (years) (SD) }\end{array}$} & \multirow{2}{*}{$\begin{array}{l}\text { Mean gross } \\
\text { motor t-score }\end{array}$} & \multirow{2}{*}{$\begin{array}{l}\text { Mean fine } \\
\text { motor t-score }\end{array}$} \\
\hline & & type & No. & $\begin{array}{c}\text { Mean age } \\
\text { (years) (SD) }\end{array}$ & & & & \\
\hline \multirow{2}{*}{20} & \multirow{2}{*}{3.75} & Male & 16 & $3.75( \pm 0.44)$ & $2.74( \pm 0.51)$ & $1.82( \pm 0.38)$ & $43.00( \pm 11.73)$ & $41.50( \pm 7.2)$ \\
\hline & & Female & 4 & $3.75( \pm 0.50)$ & $3.00(0.42)$ & $1.60( \pm 0.54)$ & $45.50( \pm 14.97)$ & $43.00( \pm 9.2)$ \\
\hline
\end{tabular}

The table described the socio-demographic data of the case group. There was a non-significant statistical difference between the mean values of different variables of both sexes among the control group, i.e. (age, receptive language age, expressive language age, mean value of t-score of the gross motoric abilities, and the mean value of t-score of the fine motoric abilities). The significance of differences between these variables $(P=1.00,0.366,0.346,0.71,0.728)$ consecutively.

Table 3: The table compared the control group and SLI group as regard (mean age, mean receptive, mean expressive, mean developmental gross motor t-score and mean developmental fine motor t-score)

\begin{tabular}{lcccc}
\hline variable & Control & Case & t test & $P$ value \\
\hline Age (years) & $3.80( \pm 0.40)$ & $3.75( \pm 0.44)$ & 0.436 & 0.664 \\
Mean receptive language age (years) & $3.45( \pm 0.49)$ & $2.79( \pm 0.49)$ & $<.489$ & 8.293 \\
Mean expressive (years) & $3.58( \pm 0.49)$ & $1.78( \pm 0.41)$ & 4.852 & $<0.001^{* *}$ \\
Mean gross motor (t-score) & $59.00( \pm 4.68)$ & $43.50( \pm 11.73)$ & 41.80 & $<.037$ \\
Mean fine motor (t-score) & 55.45 & $<0.001^{* *}$ & \\
\hline
\end{tabular}

The table compared between the two studied groups in their mean chronological age, mean receptive language age, mean expressive language age, mean gross motor developmental quotient t-score and the fine motor developmental quotient t-score).

Table 4: Motoric developmental assessment of studied patients with SLI gross motor and fine motor:

\begin{tabular}{lccc}
\hline & & No & $\%$ \\
\hline & Normal & 6 & $30.0 \%$ \\
Gross motor (descriptive severity) & Mild delay & 13 & $65.0 \%$ \\
& Significant delay & 1 & $5.0 \%$ \\
\hline & Total & 20 & $100 \%$ \\
\hline \multirow{3}{*}{ Fine motor (descriptive severity) } & & No & $\%$ \\
& Normal & 4 & $20.0 \%$ \\
& Mild delay & 15 & $75.0 \%$ \\
& Significant delay & 1 & $5.0 \%$ \\
\hline
\end{tabular}


Table 5: Correlation between developmental quotient (of the gross motor abilities and fine motor abilitiesand variables (age, sex, mean receptive mean expressive and type of SLI)

\begin{tabular}{lcccc}
\hline variable & r of gross motor develop & $P$ value & r of fine motor develop) & $P$ value \\
\hline Age & .322 & $0.012^{*}$ & .226 & .083 \\
Mean receptive & .529 & $<0.001^{* *}$ & .515 & $<0.001^{* *}$ \\
Mean expressive & .669 & $<0.001^{* *}$ & .701 & $<0.001^{* *}$ \\
\hline
\end{tabular}

$\mathrm{r}=$ Pearson correlation

The table showed that there is a Significant positive correlation between the developmental quotient of the gross motor abilities of children with SLI and their chronological age, mean receptive language age, and the mean language age. The strongest one was for expressive language age). There is also a Significant positive correlation between the developmental quotient of the fine motor abilities of children with SL and their chronological age, mean receptive language age, and the mean language age. The strongest was for expressive language age.

Table 6: compared between the developmental quotient (t-score) among different SLI Sub-types.

\begin{tabular}{lccc}
\hline Variable & Mean of gross motor developmental quotient) (t-score) & $p$ value & Mean of fine motor \\
\hline Phon. Prog. SLI & 45.00 & 40.62 \\
Synt. Phon. SLI & 43.12 & 0.872 & 40.50 \\
Sem. Pragm. SLI & 41.25 & 46.75 \\
\hline
\end{tabular}

The table showed that there is no significant statistical difference between different SLI sub types.

\section{DISCUSSION}

Children with SLI are group of children who showed a significant impairment in language acquisition despite of having all the factors that secured normal language development. SLI is a category of disorders which is non-syndromic with no known etiology. Rather the diagnosis is reached through objective test. It requires assessment of the behavior and skills. ${ }^{[32]}$ In Egypt, Sallam ${ }^{[33]}$ estimated that the prevalence of SLI among preschool children was around $17 \%$ compared to $7 \%$ in Tomblin et $a .^{[34]}$ and $2 \%$ in Villanueva et al. ${ }^{[35]}$. Gad-Allah et al. ${ }^{[36]}$ drew a special attention to language disorders among preschoolers in Egypt. Their work revealed that $30 \%$ of their sample had language disorders and up to $19.7 \%$ were of unidentified causes. The authors raised a special attention to the magnitude of the problem in the preschool children. Reilly et $a l .{ }^{[37]}$ reported that differences in the assessment tools and lack of agreement about the terminology make it difficult to compare the prevalence of SLI among different works.

The high degree of terminology disagreement regarding Specific Language Impairment may indicate that the process of understanding language disorder of unidentified causes is ongoing. ${ }^{[38]}$

The developmental profile of children with SLI took a considerable interest in the scientific field. Data obtained from these researches build a theoretical back ground to make a deeper understanding of such language disorder. Developmental assessment of SLI was carried since $1960^{[39]}$. Developmental assessment tools ranged from parent report to assessment through standardized test. The current work utilized one of the standardized developmental assessment tools in Egypt which is a standardized developmental scale among Egyptian preschool children ${ }^{[25]}$.

The current work demonstrated that $80 \%$ of the current sample were males. The previous Epidemiological studies of SLI showed predominance of boys with a ratio 2.8:1. However, this ratio is not constant and it differs from one type of SLI to another. In phonological programming it is $4: 1$. In expressive subtypes it is $3: 1$. The ratio decreased in receptive disorder and reached 2.6:1 and in mixed type it is 3:1. This finding matched what has been reported by Rabin and Allen ${ }^{[30]}$.

The current work showed that the $75 \%$ of cases was presented at the age of school entry. Research work showed that isolated phonological and expressive sub-types were mainly presented at preschool age. However, mixed receptive and expressive subtypes were presented at school entry age. Leonard and Hill[ ${ }^{[4]}$ demonstrated in their work that motor development was investigated in children with neurodevelopmental disorder at the age of school entry due to late presentation of these disorders.

The current work demonstrated that phonological programming and syntactic phonological types was the main type of SLI (i.e. $40 \%$ for each type). However, semantic pragmatic sub-type was among $20 \%$. Rabin and Allen ${ }^{[30]}$ reported that the largest number of SLI sub-types referred to syntactic phonological sub-type. 
The current work hypothesized that children with SLI usually have a developmental sub-normality in other areas other than language and specificity of language impairment rarely occur among this population. Laasonen et $a l \cdot{ }^{[40]}$ determined that language disorder of unidentified etiology is better named developmental delayed language development (DLD) in order to make a closer understanding of many developmental deficits among those children. This might aid much in making a scientific update in the comprehensive assessment and intervention strategies that should be extended to other disciplines and not limited to a language deficit.

The multiple developmental deficit theory of the SLI was supported in many aspects ${ }^{[41]}$. Pennington and Bishop ${ }^{[41]}$ supposed that significant prevalence of developmental disorders among SLI relatives supported the developmental nature of the disorder. Furthermore, several studies claimed that the remediation program that is introduced to children with SLI is not sufficient and many of SLI individuals suffered from the sequelea of SLI which is persistent language impairment Conti-Ramsden et al. ${ }^{[43]}$. Such finding may draw the attention to the presence of accompanying deficits.

The motor abilities in the current work were assessed and developmental quotients in the areas of Gross motor development and Fine motor development were determined. Results showed that gross motor development was mildly impaired in $65 \%$ of the studied sample whereas; the fine motor development was mildly compromised in $75 \%$ of the studied sample. Such findings went with a comprehensive literature review by Hill1 ${ }^{[7]}$. The study revealed that the prevalence of motor impairment among children with SLI was much higher than the earlier work had suggested. Leonard and Hill[ ${ }^{[4]}$ reported that most common figure being around $70 \%$.

The fine motor developmental quotient among the current work was supported by Bishop ${ }^{[44]}$ and Leonard et al. ${ }^{[45]}$. They found that the speed of tapping is compromised in children with SLI compared to normally developing children. The second author generalized this finding to any task that requires speeded information processing.

Different motoric profile among children with SLI was reviewed by Hill1 ${ }^{[7]}$ mainly: (the gross motor ${ }^{[4,46]}$, fine motor ${ }^{[47-49]}$ praxis abilities ${ }^{[50-52]}$ and articulatory speech motor acts). ${ }^{[39]}$

The effect left by the motoric deficits among SLI children on daily activities was examined by Hannus et $a l .{ }^{[53]}$. They examined the home activities of children with SLI and compared their results to the typically developing children. They found that children with
SLI have frequent changeability of daily activities and fewer activities of playing outdoors. They explained such findings by poor planning of play activity, impaired social-pragmatics skills and thinking and reasoning problems among these children.

The current work found that there are significant correlations between the gross motor developmental score and the receptive language age as well as the expressive language age of the children with SLI. Leonard and Hill ${ }^{[4]}$ supported these findings.

This significant correlation was supported also by Finlay and McPhillips ${ }^{[54]}$. The authors reported that about one third of children with SLI were presented with noticeable motor difficulties and half of them received the label of at risk for motor difficulties. Flapper and Schoemaker ${ }^{[55]}$ offered similar results. Vukovic et al. ${ }^{[56]}$ showed that children with SLI scored significantly lower on measures of coordination and imitation in comparison to their age-matched typically developing peers.

Zelaznik and Goffman ${ }^{[57]}$ examined different aspects of fine motoric abilities of children with SLI (motoric timing). They found that children with SLI performed more poorly than age-matched typically developed children across several coordination based tasks.

In spite of the absence of motor speech assessment of children with SLI, several work supported a significant findings ${ }^{[58]}$. Gesture production, motor ability and fine motor abilities among children with SLI were examined by Botting et al. ${ }^{[59]}$ \& Iverson and Braddock $^{[60]}$. Their results indicated that children with SLI performed poorly across all measures of motor abilities and their fine motor abilities were directly related to their language scores. However, gesture production among their sample of SLI children was inversely correlated to expressive language ability for the children with SLI. Based on these findings, Iverson and Braddock $^{[61]}$ recommended the importance of preschool screening of SLI using motor abilities and gesture usage.

Interconnected brain network throw which the language area in the brain is extensively connected to other brain areas could explain the co-association of language and motoric deficit. Several works showed that impaired abstract cognitive process provides the bases of motoric and linguistic impairment in children with SLI. Such findings could explain the discrepancy between motoric performance in simple activities like gestural communication and complex motoric activities that requires higher cognitive abilities like sequencing motor act that may be disrupted in SLI Iverson and Braddock ${ }^{[61]}$. 
The theoretical background of the nature of SLI started to be clearly understood. Sequencing deficits of motor planning among SLI children was the backbone theory of SLI. ${ }^{[48,62,63]}$

Motor sequencing act deficit among SLI children was supported by Ullman and Pierpont ${ }^{[64]}$. However, the possibility of the accidental occurrence of deficits in the motoric and language areas was supported by others. Therefore, Future research work would support either one of the two previously mentioned hypotheses. ${ }^{[65]}$

The theoretical bases of the relation between language deficit and motoric deficit were explained on the bases of procedural memory deficit mainly sequencing deficit. Procedural memory is a cognitive capacity that enables automatic skills acquisition $^{[66]}$. It is the function of striatum and frontal region $^{[62,67]}$. Hus and Bishop ${ }^{[68]}$ and Nicolson \& Fawcett ${ }^{[69]}$ supported the presence of sequencing deficit which underlies the motoric and language deficit in children with SLI. Based on this view, authors claimed that assessment of procedural memory aspect of motoric abilities act as a non-linguistic marker that could predict language deficit among children at risk for SLI (e.g. Bilinguism ${ }^{[70]}$ ).

They assumed that several language parameters (e.g. syntax, semantics, phonology and pragmatics) need intact procedural learning skills specifically sequencing learning. At the same time it is essential in learning the motor act. ${ }^{[71]}$ Gabriel et al. ${ }^{[72]}$ were in disagreement with this point of view. After that many research work launched out procedural hypothesis of SLI which entailed that procedural learning and memory deficit was the backbone for development of SLI.

Severity of SLI is essential in drawing a complete profile for this population. The severity of SLI among the current work was assessed by application of language test. Receptive language age in the range of 1 year-1 year 6 months less than the chronological age was reported among 55\% of the current work sample. While the gap in expressive language age was in the range between 2 years and 2 years 6 months less than the chronological age among $85 \%$ of cases. It is clear that expressive language difficulties were the main presentation of children with SLI among the current work. Hannus ${ }^{[53]}$ reported that parent's interview is essential in identifying severity of language disorders.

Severity of SLI among scientific work was measured in many different ways. The child's ability to participate in life according to the principles of International Classification of Functioning, Disability and Health $(\mathrm{ICF})^{[73]}$ was one of highly considered measures of assessment of the disorder severity.
Other viewed that difficulty in receptive skills leads to more sever clinical presentation and poor outcome than expressive language deficit ${ }^{[32]}$. Hannus et al. ${ }^{[74]}$ argued that evaluation of the severity of the language disorder should consider the child's performance in different life aspects (e.g. his/her activities at home, social relation, emotional development, and academic achievement). Such point of view is supported by the current work. The current work found that there is a significant direct correlation between the receptive language age and expressive language age and the gross and fine motoric score.

The current work determined that several factors were related to the presentation of motoric deficit in SLI children. The first was the late age of presentation and the mean receptive and expressive language age. Further work should be directed towards longitudinal studies which assess early motoric development and relate it to other developmental domains (cognitive, social, and communication $)^{[75]}$. Literature claimed that late presentation of children with SLI make an early identification and intervention of many associated disorders a difficult task.

\section{CONCLUSION}

The complex relationships between motor skills and communicative skills require more attention. Early developmental assessment would develop a well-tailored intervention program that address early affected skills and improve the outcome of late developing skills. This could add further explanation for variability of linguistic strength and weakness in children with language difficulties of unknown etiology.

\section{CONFLICT OF INTEREST}

There are no conflicts of interest.

\section{REFERENCES}

1. Wang MV, Lekhal R, Aarø LE, Schjolberg S. Co-occurring development of early childhood communication and motor skills: results from a population-based longitudinal study. Child: Care, Health and Development 2012; 40(1): 77-84.

2. Iverson J, Braddock BA. Gesture and Motor Skill in Relation to Language in Children With Language Impairment Journal of Speech, Language, and Hearing Research 2011;54: 72-86.

3. Cheng H, Chen H, Tsai C, Chen Y, Cherng R. Comorbidity of motor and language impairments in preschool children in Taiwan. Research in Developmental Disabilities 2009; 30: 1054-61.

4. Leonard HC, Hill EL. The impact of motor development on typical and atypical social cognition and language: 
A systematic review. Child \& Adolescent Mental Health 2014; 19(3):163-70 (John Wiley \& Sons Ltd).

5. Iverson JM. Developing language in a developing body: the relationship between motor development and language development. Journal of Child Language 2010; 37(02), 229-261.

6. Karasik LB, Tamis-Le Monda CS, Adolph KE. Transition from crawling to walking and infants' actions with objects and people. Child Development 2011; 82: 1199-1209.

7. Clearfield MW, Osborne CN, Mullen M. Learning by looking: Infants' social looking behavior across the transition from crawling to walking. Journal of Experimental Child Psychology 2008; 100: 297-307

8. Campos JJ, Anderson DI, Barbu Roth MA, Hubbard, EM, Hertenstein MJ, Witherington D. Travel Broadens the Mind. Infancy 2000; 1: 149-219.

9. Libertus K, Needham A. Teach to reach: The effects of active vs. passive reaching experiences on action a and perception. Vision Research 2010; 50: 2750- 2757.

10. Libertus, K., Needham, A. Reaching experience increases face preference in 3-month-old infants. Developmental Science 2011; 14: 1355-1364.

11. MacNeilage PF. The origin of speech. Oxford, England: Oxford University Press; 2008.

12. Gernsbacher MA, Sauer EA, Geye HM, Schweigert EK, Goldsmith HH. Infant and toddler oral- and manual-motor skills predict later speech fluency in autism. Journal of Child Psychology and Psychiatry 2008; 49: 43-50.

13. Merriman WJ, Barnett BE. A preliminary investigation of the relationship between language and gross motor skills in preschool children. Perceptual and Motor Skills 1995; 81: 1211-1216.

14. Arbib MA. Action to Language via the Mirror Neuron System. MA: Cambridge University Press; Cambridge, 2006

15. Kent RD. Models of speech motor control: Implications from recent developments in neurophysiological and neurobehavioral science. In: Maasen, B.; Kent, R.; Peters, H.; van Lieshout, P.; Hulstijn, W., editors. Speech motor control in normal and disordered speech. Oxford: Oxford University Press; 2004. p. 3-28

16. Diamond A. Close interrelation of motor development and cognitive development and of the cerebellum and prefrontal cortex. Child Development 2000; 71, 44-56.

17. Hill EL. Non-specific nature of specific language impairment: A review of the literature with regard to concomitant motor impairments. International Journal of Language and Communication Disorders, 2001 36:149-171.

18. Weismer SE, Evans J. Hesketh LJ. 'An examination of verbal working memory capacity in children with specific language impairment', Journal of Speech, Language, and Hearing Research 1999; 42 (5): 1249-60

19. McGregor KK, Leonard LB. Subject pronoun and article omissions in the speech of children with specific language impairment: A phonological interpretation. Journal of Speech and Hearing Research 1994; 37:171-181.

20. Goffman L. Prosodic influences on speech production in children with specific language impairment. Journal of Speech, Language, and Hearing Research 1999; 42:1499-1517.

21. Goffman L. Kinematic differentiation of prosodic categories in normal and disordered language development. Journal of Speech, Language, and Hearing Research 2004; 47:1088-1102.

22. Abu El-Leel, M., Taha M., Ismaeel A. Instruction notebook Stanford-Binet Intelligence Scale, fifth edition. The Arab foundation for legalization and preparation of psychological tests. Cairo, 2011.

23. Sparrow SS, Balla DA, Cicchetti DV. Vineland Adaptive Behavior Scales. Circle Pines, MN: American Guidance Service. 1984.

24. Abu Hasseba A. Standardization, Translation and Modification of the Preschool Language Scale-4. Unpublished $\mathrm{Ph}$. D. Dissertation. Ain Shams University, Cairo 2011.

25. Ismaeel E, Kazem A, Ramzy N et al. Pre-school child development standards. National committee of childhood and mother, Cairo1994.

26. Sanford AR, Janet G, Zeimer JG. The learning Accomplishment profile (LAP) Chapel Hill Trainingoutreach project. Winston-Salem, N.C: Kaplan Press.1981.

27. Glover ME. Preminger JL, Sanford AR. The Early Learning Accomplishment Profile for Developmentally Young Children: Birth to 36 months Manual Revised edition. Lewisville, NC: Kaplan Press. 1995-a

28. Glover ME, Preminger JL, Sanford AR. Early LAP scoring booklet - Revised. Lewisville, NC Kaplan Press. 1995-b

29. Barnes KE. Preschool screening: The measurement and prediction of children at-risk. Springfield, IL: Thomas. 1982 
30. Rapin I, Allen D. Developmental dysphasia and autism in preschool children - characteristics and subtypes. Proceedings of the first international symposiun on specific speech and language disorders in children. London association for all speech impaired children, 1987.

31. Field A. Discovering statistics using SPSS. 3rd ed. London: SAGE Publications Ltd; 2009.

32. Hannus, S. Child with SLI in primary health care Department of General Practice and Primary Health Care Clinic, Faculty of Medicine University of Helsinki Finland, Children with specific language impairment in primary health care - tests, assessment, prevalence and home activities, Academic Dissertation Helsinki 2018.

33. Sallam, Y.A. Prevalence of subtypes of specific language impairment. Unpublished doctoral dissertation, Faculty of Medicine. Ain Shams University, Cairo, Egypt; 2011.

34. Tomblin JB, Records NL, Buckwalter P, Zhang X, Smith E, O’Brien M. Prevalence of specific language impairment in kindergarten children. Journal of speech, language, and hearing research JSLHR 1997; 40(6):1245-60.

35. Villanueva P, de Barbieri Z, Palomino HM, Palomino $\mathrm{H}$. High prevalence of specific language impairment in Robinson Crusoe Island. A possible founder effect. Revista medica de Chile 2008; 136(2):186-92.

36. Gad-Allah H, Abd-Elraouf S, Abou-Elsaad T, AbdElwahed M. Identification of communication disorders among Egyptian Arabic-speaking nursery schools' children. Egyptian Journal of Ear, Nose, Throat and Allied Sciences 2012; 13(2): 83-90.

37. Reilly S, Tomblin B, Law J, McKean C, Mensah FK, Morgan A, Wake M. Specific language disorder: A convenient label for whom?: SLI: A convenient label for whom? International Journal of Language \& Communication Disorders 2014; 49: 416-451.

38. Hons JCB. Developmental language disorders: a longitudinal study of cognitive, social, and psychiatric. Thesis submitted to the degree of Doctor of Philosophy in Developmental Psychiatry, Division of Psychiatry University of Nottingham, December 2001.

39. Sanjeevan T, Rosenbaum DA, Miller C, Janet G, van Hell V, Weiss D J, Arnold EM. Motor Issues in Specific Language Impairment: a Window into the Underlying Impairment. Curr Dev Disord Rep 2015; 2:228-236.

40. Laasonen M, Smolander S, Lahti-Nuuttila P, Leminen M, Lajunen HR, Heinonen K, Pesonen AK, Bailey TM, Pothos EM, Kujala T, Leppänen P HT, Bartlett CW, Geneid A, Lauronen L, Service E, Kunnari S
Arkkila E. Understanding developmental language disorder-The Helsinki longitudinal SLI study (Hel SLI): A study protocol. BMC Psychology, 6(1).

41. Li N, Bartlett CW. Defining the genetic architecture of human developmental language impairment. Life Sci 2012; 90 (13-14): 469-75.

42. Pennington BF, Bishop DVM. Relations among speech, language, and reading disorders. Annu Rev Psychol 2009; 60:283-306.

43. Conti-Ramsden G, Mok PLH, Pickles A. et al. Adolescents with a history of specific language impairment (SLI): strengths and difficulties in social, emotional and behavioral functioning. Res Dev Disabil, 2013; 34(11): 4161-69.

44. Bishop DVM. Motor immaturity and specific speech and language impairment: evidence for a common genetic basis. Am J Med Genet. 2002; 114: 56-63

45. Leonard LB, Ellis Weismer S, Miller CA, Francis DJ, Tomblin JB, Kail RV. Speed of Processing, Working Memory, and Language Impairment in Children. Journal of Speech Language and Hearing Research 2007;50: 408-428.

46. Johnston RB, Stark RE, Mellits ED, et al. Neurological status of language-impaired and normal children. Ann Neurol 1981; 10: 159-63.

47. Katz WF, Curtiss S, Talla 1P. Rapid automatized naming and gesture by normal and language-impaired children. Brain Lang 1992; 43: 623-41.

48. Owen SE, McKinlay IA. Motor difficulties in children with developmental disorders of speech and language. Child Care Health Dev 1997; 23:315-25.

49. Powell RP, Bishop DVM. Clumsiness and perceptual problems in children with specific language impairment. Dev Med Child Neurol 1992; 34:755-65.

50. Dewey D, Wall K. Praxis and memory deficits in language impaired children. Dev Neuropsychol 1997; 13: $507-12$.

51. Hill EL. A dyspraxic deficit in specific language impairment and developmental coordination disorder? Evidence from hand and arm movements. Developmental Medicine \& Child Neurology 1998; 40(6): 388-395.

52. Hill EL, Bishop DVM, Nimmo-Smith I. Representational gestures in developmental coordination disorder and specific language impairment: error-types and the reliability of ratings. Hum Mov Sci 1998; 17:655-78. 
53. Hannus S, Kauppila T, Launonen K. Type and Duration of Home Activities of Children with Specific Language Impairment: Case Control Study Based on Parents' Reports. Child Development Research.2016

54. Finlay JCS, McPhillips M. Comorbid motor deficits in a clinical sample of children with specific language impairment. Res Dev Disabil 2013; 34: 2533-42.

55. Flapper BCT, Schoemaker MM. Developmental coordination disorder in children with specific language impairment: co-morbidity and impact on quality of life. Res Dev Disabil 2013; 34: 756-63.

56. Vukovic M, Vukovic I, Stojanovik V. Investigation of language and motor skills in Serbian speaking children with specific language impairment and in typically developing children. Research in Developmental Disabilites 2013; 31: 1633-1644.

57. Zelaznik HN. Goffman L. Generalized motor abilities and timing behavior in children with specific language impairment. J Speech Lang Hear Res, 2010; 53(4): 383-93.

58. Andrade CRF, Befi-Lopes DM. Juste FS, et al. Aspects of speech fluency in children with specific language impairment. Audiol Commun Res 2014; 19(3): 252-7.

59. Botting N, Riches N, Gaynor M. et al. Gesture production and comprehension in children with specific language impairment. Br J Dev Psychol. 2010; 28: 51-69.

60. Iverson JM, Braddock BA. Gesture and motor skill in relation to language in children with language impairment. Journal of Speech, Language, and Hearing Research, 2006; 54: 72-86.

61. Iverson JM, Braddock BA. Gesture and Motor Skill in Relation to Language in Children With Language Impairment. Journal of Speech, Language, and Hearing Research 2011; 54: 72-86.

62. Doyon I, Owen AM, Petrides M, Sziklas V, Evans AC. Functional anatomy of visuomotor skill learning in human subjects examined with positron emission tomography. European Journal of Neuroscience 1996; 8: 637-648.

63. Brumbach ACD, Goffman L. Interaction of language processing and motor skill in children with specific language impairment. J Speech Lang Hear Res 2014; $57: 158-71$.

64. Ullman MT, Pierpont EI. Specific language impairment is not specific to language: the procedural deficit hypothesis. Cortex 2005; 41: 399-433.
65. Tomblin JB, Buckwalter PR. Heritability of poor language achievement among twins. J Speech Lang Hear Res, 1998; 41:188-99.

66. Bishop DV, Chan J, Adams C, Hartley J, Weir F. "Conversational responsiveness in SLI. Evidence of disproportionate pragmatic difficulties in a subset of children," Journal of Psychopathology 2000; 12 (2):177-199.

67. Ferraro FR, Balota DA, Connor LT. Implicit memory and the formation of new associations in non-demented Parkinson's disease individuals and individuals with senile dementia of the Alzheimer type: a serial reaction time (SRT) investigation. Brain and Cognition 1993; 21: 163-180.

68. Hsu HJ, Bishop DVM. Grammatical difficulties in children with specific language impairment: is learning deficient? Human Development 2011; 53: 264-277.

69. Nicolson R, Fawcett AJ. Procedural learning difficulties: reuniting the developmental disorders? Trends Neurosci 2007; 30(4):135-41.

70. Bedore LM, Pena ED. Assessment of bilingual children for identification of language impairment: current findings and implications for practice. Int $\mathrm{J}$ Biling Educ Biling. 2008; 11(1):1-29.

71. Hedenius M, Persson J, Tremblay A, Adi-Japha E, Verissimo J, Dye CD, Alm P, Jennische M, Tomblin JB, Ullman MT. Grammar predicts procedural learning and consolidation deficits in children with specific language impairment. Research in Developmental Disabilities 2011; 32, 2362-2375.

72. Gabriel A, Maillart C, Stefaniak N, et al. Procedural learning in specific language impairment: effects of sequence complexity. J Int Neuropsychol Soc. 2013;19(3):264-71.

73. World Health Organization. International Classification of Functioning, Disability and Health (ICF). Geneva: WHO.2001.

74. Hannus S, Kauppila T, Pitkäniemi J \& Launonen $\mathrm{K}$. Use of language tests when identifying specific language impairment in primary health care. Folia Phoniatrica et Logopaedica 2013; 65:40-46.

75. Viholainen $\mathrm{H}$, Ahonen $\mathrm{T}$, Lyytinen $\mathrm{P}$, Cantell M, Tolvanen A, Lyytinen H. Early motor development and later language and reading skills in children at risk of familial dyslexia. Dev Med Child Neurol 2006; 48: $367-373$. 